Mariana Beatriz Mataluna

Universidad de Buenos Aires, Argentina

E-mail: marianamataluna@gmail.com

(D) https://orcid.org/0000-0002-4632-3652

\section{A Escola de Aplicação da Universidade de São Paulo: um caso bem sucedido de ensino médio público}

\author{
Mariana Beatriz Mataluna
}

\section{Resumo}

O presente artigo tem por objetivo contribuir para o debate sobre a funcionalidade do ensino médio por meio da análise de um caso bem sucedido de instituição escolar, as escolas ou colégios de aplicação dependentes de universidades públicas. $\mathrm{O}$ estudo forma parte de uma pesquisa mais ampla realizada para a elaboração de tese de doutorado, focada no caso particular da Escola de Aplicação da Faculdade de Educação de Universidade de São Paulo. O texto abrange o período entre 2014 e 2016, momento crucial da recente história brasileira, no qual os graves problemas estruturais do sistema educacional se materializaram em protestos que culminaram em ocupações, pelos estudantes, de instituições públicas de ensino secundário. A metodologia utilizada inclui análise bibliográfica, de documentos e de legislações, além do trabalho de campo envolvendo entrevistas a professores e alunos. O estudo de caso possibilita chegar à conclusão de que quando a escola oferece ensino de qualidade, com professores comprometidos e qualificados, os alunos não questionam sua relevância para o seu futuro.

Palavras-chave: Ensino médio. Escolas de aplicação. Universidade de São Paulo.
Recebido em: 15/03/2019

Aprovado em: 17/07/2019 


\begin{abstract}
The School of Application of the University of São Paulo: a successful case of public high school

This article aims to contribute to the debate about the functionality of secondary education through the analysis of schools dependent on public universities. This study is part of a larger research project carried out for the development of a doctoral thesis, focused on particular case of a school dependent on the University

Keywords:

High school. Colleges

dependent on public

universities. São

Paulo of São Paulo ("Escola de Aplicação"). The analytical cut covers the years 2014 to 2016, a crucial period in recent Brazilian history, in which the serious structural problems of our educational system materialized in protests that culminated in the occupation of public schools by secondary students. The methodology used includes bibliographic analysis, documents and the examination of legislation, as well as fieldwork, which constitutes interviews with teachers and students. The findings support that when a school offers quality education with committed and trained teachers, students do not question its importance to their future.
\end{abstract}

University.

\section{Resumen}

Palabras clave: Educación secundaria. Escuelas de aplicación. Universidad de São Paulo.

La "Escola de Aplicação" de la Universidad de São Paulo: un caso exitoso de educación secundaria pública

El presente artículo tiene por objetivo contribuir en el debate sobre la funcionalidad de la educación secundaria por medio del análisis de un caso exitoso de institución escolar, las escuelas y colegios de aplicación dependientes de universidades públicas. Este estudio forma parte de una investigación más amplia realizada para la elaboración de la tesis de doctorado, focalizada en el caso particular de la Escuela de Aplicación de la Universidad de Sao Paulo. El recorte analítico abarca 2014-2016, período crucial de la reciente historia brasilera, en el cual graves problemas estructurales del sistema educativo irrumpieron en protestos incluyendo ocupaciones de escuelas públicas por los propios estudiantes. La metodología utilizada incluye análisis bibliográfico, de documentos y de legislaciones, además de un trabajo de campo incluyendo entrevistas a profesores y estudiantes. El estudio de este caso, posibilitó concluir que cuando la escuela ofrece educación de calidad, con profesores comprometidos y calificados, los estudiantes no cuestionan su importancia para su futuro. 


\section{Introdução}

No Brasil (assim como em outros países ${ }^{1}$ ), a funcionalidade do ensino médio é constantemente questionada e o nível secundário é objeto de repetidas reformas que visam sua “adequação” aos tempos e exigências do mercado de trabalho. Por um lado, os índices de evasão escolar dos jovens no sistema público de ensino e as baixas notas alcançadas nos índices de avaliação da educação brasileira fornecem incessante munição a seus críticos e reformadores. Por outro lado, não se pode deixar de atentar para a crescente concentração e internacionalização da educação privada em nossos países, com todos os interesses, lobbies e grupos de pressão envolvidos.

O sistema educacional brasileiro, marcado pela dualidade entre o sistema público e o privado, é um instrumento altamente eficiente de preservação das desigualdades. No interior mesmo do sistema estatal ainda permanece certa segregação e separação dos públicos escolares: em algumas instituições - às quais assistem parcela dos setores privilegiados - a transmissão escolar garante o acesso a saberes relevantes; em outras escolas (a grande maioria), frequentadas pelos setores de renda média-baixa e baixa da população, a prática escolar não proporciona integralmente esse acesso, comprometendo a articulação dos estudantes secundaristas com o ensino superior ou com melhores posições no mercado de trabalho.

Há alguns anos se observa, em diferentes regiões do globo, crescente insatisfação com a educação pública em geral, insatisfação que se manifesta em massivas demonstrações de estudantes, particularmente "secundaristas", bem como em ocupações de escolas, com o objetivo de reivindicar melhores condições do ensino público, maior participação no debate sobre reformas propostas (e impostas pelo Estado), ou mesmo impedir o fechamento de escolas e garantir o acesso ao nível superior gratuito, entre outras pautas. Essas manifestações colocam na ordem do dia a educação como direito democrático e popular.

Diferentes autores (KUENZER, 1997; REZENDE PINTO, 2002) coincidem em apontar que o nível médio seria o mais afetado pelas mudanças contextuais e de mandatos ao qual o sistema educacional é submetido. Este nível é frequentemente diagnosticado, por muitos especialistas, consultores e formadores de opinião, como um âmbito particularmente atravessado pela "perda de sentido”.

Apesar de sua obrigatoriedade, não se observa, em linhas gerais, o mesmo consenso na sociedade sobre a funcionalidade/necessidade do nível médio, em comparação com os níveis 
fundamental e superior. Parte da explicação para esse "desencanto" com o ensino médio decorreria do fato de que parcela importante dos jovens em sociedades marcadas pela desigualdade não conseguem captar qual seria o sentido da escola secundaria quando suas perspectivas de ingresso à Universidade ou mesmo ao mercado de trabalho formal são extremamente limitadas.

Nesse contexto de “insatisfação generalizada” com o ensino secundário, pouco se fala dos casos bem sucedidos do sistema público (onde se destacam as escolas dependentes de Universidades) e das maneiras de se expandir esses casos para o sistema como um todo. Em recente trabalho do Instituto de Estudos Avançados da Universidade de São Paulo, essa questão é colocada de forma clara:

Ao dar mais destaque ao desempenho negativo do que aos múltiplos exemplos de boas escolas, que precisam ser reconhecidos e amplificados, nos diferentes níveis de ensino, os programas governamentais alimentam uma política de terra arrasada, deixando de apoiar parceiros importantes na busca da melhoria do ensino (IEA USP, 2018, 5).

O presente artigo recupera dados, análises e reflexões da pesquisa mais ampla realizada para elaboração de tese de doutorado defendida junto à Universidade de Buenos Aires ${ }^{2}$, e tem como tema a problemática do ensino médio no Brasil e o papel, nesse contexto, das escolas ligadas às Universidades públicas. Seu objetivo é contribuir para o debate sobre um projeto de educação democrática, inclusiva e de qualidade, aspiração geral de qualquer sociedade, e cujo principal beneficiário é a grande parcela da população que só possui como alternativa educacional o sistema público de ensino.

Nesse sentido, o artigo está formado por três partes, além desta Introdução e das Considerações Finais. Na primeira parte, é traçada uma trajetória das mais recentes reformas do ensino médio, tendo em conta seu aparente “fracasso” em atender às diversas expectativas dos jovens que o frequentam. Em seguida, é apresentado o caso das escolas dependentes de Universidades, indicando suas singularidades e diferencias no universo do sistema de ensino público. A terceira parte, por sua vez, é dedicada ao caso da Escola de Aplicação da Faculdade de Educação da Universidade de São Paulo (FE-USP). Por fim, são apresentadas algumas considerações finais, buscando explicitar as potencialidades do caso analisado para a superação de uma suposta “perda de sentido” do ensino médio, considerando sua universalização como uma legítima aspiração social, tendo em conta que relegar os jovens de famílias economicamente desfavorecidas a alguns poucos anos de educação básica seria legitimar o quadro de segregação socioeconômica historicamente dominante no Brasil. 


\section{Um nível educacional "em constante reforma"}

Das instituições de ensino se espera um conjunto de resultados, nem sempre compatíveis: o fornecimento de mão de obra (muito ou pouco) qualificada para o mercado de trabalho, a formação de futuros pesquisadores e produtores de conhecimento, bem como das elites dirigentes, cidadãos conscientes/autônomos/participativos/ solidários, etc. Não obstante, essas instituições parecem estar sempre atrasadas em termos de uso de tecnologias, adaptação às exigências do "mercado" e às transformações socioeconômicas/culturais, ou simplesmente no atendimento das aspirações dos jovens que as frequentam. Nesse contexto, questionamentos ao funcionamento e eficiência do sistema educacional secundário, bem como propostas de reformas, estão quase sempre na ordem do dia.

A década de 1990 foi marcada, no Brasil e em grande parte da América Latina, por um processo de reestruturação do Estado, baseado e caracterizado pela globalização do capital, pelo predomínio de uma retórica e prática neoliberais, pela predominância dos fluxos financeiros internacionais, pelo surgimento de novos paradigmas produtivos e organizacionais que contribuíram para una precarização das condiciones de trabalho. O processo de restruturação econômica se combinou com propostas de reforma do Estado, sobretudo por meio de seu “enxugamento” na área produtiva (privatizações), busca de menor intervenção e regulação das atividades econômicas e das relações laborais, reforma do sistema previdenciário e diminuição de gastos em saúde e educação.

Paradoxalmente, é na década de 1990 que a democracia se consolida na maioria dos países latino-americanos, o que possibilitou a importante parcela da população sua mobilização para eleição de seus governantes e a luta pela ampliação e/ou preservação de seus direitos.

Em 1988, a sanção de uma nova Constituição Federal (CF) ativou transformações na educação brasileira. Com o objetivo de harmonizar a lei sobre educação com a CF, se inicia um longo processo de discussão, no qual diferentes forças e segmentos socioeconômicos se enfrentaram em defensa de interesses muitas vezes antagônicos, até a sanção, em 1996, da “Lei de Diretrizes e Bases da Educação Nacional n 9.394/96” (LDB/96).

O debate no âmbito legislativo (entre 1988 e 1996) acabou por favorecer, na nova LDB, interesses dos setores ligados à educação privada e da igreja católica em detrimento de alguns importantes ideais ligados à escola pública, laica e democrática (OLIVEIRA, 1999). A nova lei trouxe mudanças significativas em termos de financiamento, oferta, gestão e organização do sistema educacional. 
Com relação ao nível secundário, a mais importante modificação relacionou-se com sua cobertura, ao estabelecer "a progressiva extensão da obrigatoriedade e gratuidade ao ensino médio”, em um prazo razoável, com sua oferta sob responsabilidade basicamente dos estados, cabendo ao governo federal equiparar as oportunidades regionais e garantir um padrão mínimo de qualidade do ensino mediante assistência técnica e financeira (CF, art. 211 e LDB, art.10). O nível secundário passou a ser considerado parte da “educação básica”.

Com respeito ao processo de avaliação, o Ministério de Educação, no contexto da nova lei, criou o Exame Nacional do Ensino Médio (ENEM). De função inicial diagnóstica, o ENEM passou, gradualmente, a ser utilizado como ferramenta de seleção para o ingresso nas instituições de educação superior, uma distorção em suas funções originais (REZENDE PINTO, 2002) e que, segundo alguns autores (PORTELA e ADRIÃO, 2002; ARELARO e VALENTE, 2002) tornou-se instrumento utilizado pelo governo federal para neutralizar a diversidade e a autonomia no sistema educacional, sem a necessidade de responsabilizar-se pela oferta e financiamento do ensino básico.

Como finalidades do nível médio, a LDB estabeleceu, entre outras, a consolidação e o aprofundamento dos conhecimentos adquiridos no ensino fundamental, possibilitando o prosseguimento dos estudos superiores; a preparação básica para o trabalho e a cidadania do educando; o aprimoramento do educando, incluindo a formação ética e o desenvolvimento da autonomia intelectual e do pensamento crítico. Foi estabelecida, ainda, uma base curricular comum (parâmetros curriculares nacionais), que deveria ser complementada por conteúdos ajustados às condições e clientelas locais.

O Artigo 51 da LDB/96 estabeleceu que as instituições de educação superior credenciadas como Universidades, ao deliberar sobre critérios e normas de seleção e admissão de estudantes, levariam em conta os efeitos desses critérios sobre a orientação do ensino médio, articulando-se com os órgãos normativos dos sistemas de ensino. Dessa forma, o vestibular deixaria, gradualmente, de ser a única forma de ingresso nas instituições de educação superior, sendo complementado e/ou substituído pelo ENEM e por processos seletivos “diversificados”.

Dessa forma, com o advento do ENEM e sua consolidação como meio de seleção para o ingresso no ensino superior, a responsabilidade das escolas em promover uma formação de qualidade se viu aumentada. Inicialmente pensado como instrumento para diagnóstico e melhoria do sistema nas áreas onde fossem detectadas as maiores dificuldades de aprendizagem, o ENEM se transformou, paulatinamente, em instrumento no processo seletivo para o ingresso no nível superior e em fonte de classificação das instituições educacionais. Em 
um contexto de heterogeneidade do sistema público e de clivagem público/privado, aquele exame acabou por contribuir para a manutenção da desigualdade de acesso à educação superior e a postos de trabalho de melhor remuneração, sob a justificativa da meritocracia.

Não obstante as reformas advindas da LDB/96, o ensino médio, principalmente em sua oferta pelo estado, continuou a ser questionado por importantes parcelas da sociedade, que contestavam seu caráter de manutenção das desigualdades, sua baixa qualidade (agora explicitada pelas medições do ENEM) ou mesmo sua utilidade para os jovens de famílias mais vulneráveis e com menores possibilidades de inclusão no mercado de trabalho formal ou no ensino superior.

Durante o período 2003-2010, a CF e a LDB/1996 passaram por importantes alterações, de modo que novos direitos fundamentais foram inscritos nos quadros regulatórios da educação brasileira. Resoluções, leis, decretos e emendas foram aprovadas, indicando certa hiperatividade no âmbito legal, principalmente para o nível secundário.

Ainda que a administração federal na primeira década do século XXI tenha conservado alguns dos elementos da reforma da década anterior, como o sistema de avaliação nacional e os parâmetros curriculares centrais, com modificações menores quanto à estrutura de financiamento, podemos destacar algumas mudanças significativas, como a ampliação da obrigatoriedade escolar (que passou a ser dos 4 aos 17 anos), e o aumento nos recursos financeiros destinados a educação ${ }^{3}$. Com a emenda constitucional 53/2006 foi criado o Fundo de Manutenção e Desenvolvimento da Educação Básica (FUNDEB), que possibilitou a ampliação do antigo Fundo de Manutenção e Desenvolvimento do Ensino Fundamental e de Valorização do Magistério (FUNDEF) para o financiamento de toda a educação básica, ampliando, assim, os recursos para o nível médio.

O Programa de Melhoria e Expansão do Ensino Médio, iniciado em 2000, passou a ter por objetivo a expansão da cobertura daquele nível, por meio da regularização do fluxo escolar, a redução da taxa de evasão e a melhoria da relação escola-família-sociedade, como a extensão da atividade nas escolas durante fins de semana, gerando espaços institucionalizados para a socialização dos jovens e o fortalecimento dos vínculos da escola com a comunidade.

Conforme Pereira da Silva (2011, 238), outras alterações legais criaram a obrigatoriedade do Estado em conceber e organizar as ações relativas ao "material didáticoescolar, transporte, alimentação e assistência à saúde” com vistas a atender a educação infantil, o ensino fundamental e médio, iniciativas que contribuiriam para o acesso e a permanência do aluno na escola. 
Transformar em obrigatória a educação básica, assegurando sua oferta gratuita para todos e outorgando à educação secundária o status de direito de todo cidadão foi uma decisão inovadora (ainda que tardia). Não obstante, persistiu a clivagem entre as instituições públicas e privadas, o interior do sistema educacional público continuou heterogêneo e fragmentado, os métodos de ingresso às melhores instituições de ensino superior ainda privilegiavam os alunos com melhores condições socioeconômicas e familiares.

Em setembro de 2016, o governo federal publicou a Medida Provisória (MP) $\mathrm{n}^{\mathrm{o}}$ 746/2016, modificando o modelo de educação secundária implementado ao longo dos últimos anos. Entre as principais alterações da MP, destacam-se a adoção do tempo integral e a flexibilização do currículo, com a adoção de módulos temáticos escolhidos pelos alunos, segundo seus interesses acadêmicos e/ou profissionais.

Com a MP, as disciplinas tradicionais obrigatórias - Matemática, Português, História, Química, Biologia, Artes e Educação Física - seriam oferecidas em metade da carga horária, durante os três anos do ensino médio. Na outra metade, os alunos poderiam optar por aprofundar conteúdos e temas relacionados a áreas de seu interesse (Linguagens, Matemática, Ciências da Natureza, Ciências Humanas e Formação Técnica e Profissional).

A MP foi atacada por vários setores vinculados à educação, por parcela significativa da sociedade e por um grande número de alunos secundaristas. Para os críticos da medida, além de seu caráter autoritário (pois não foi votada no legislativo), a diminuição do número de disciplinas obrigatórias produziria um esvaziamento dos conteúdos que contribuem para a formação crítica dos alunos. Em um contexto de falta de recursos financeiros, as escolas públicas em geral poderão (ou deverão) sofrer uma forte diminuição de seus quadros de professores, considerados agora como “opcionais”. O já imenso hiato entre as instituições privadas e públicas tenderá a se consolidar, senão se ampliar, em benefício dos alunos de famílias de maiores rendimentos, tendo em conta que a flexibilização do currículo seria viável somente para aquelas instituições dotadas de maiores recursos financeiros, capazes de contratar professores para as disciplinas “optativas”.

Nesse contexto, as vozes dos estudantes foram contundentes com relação à sua insatisfação com as políticas educacionais predominantes desde 2015. Em 2015 e 2016, o país vivenciou uma das maiores manifestações de “secundaristas” dos últimos quarenta anos. Milhares de alunos, por meio da auto-organização, reivindicaram a manutenção de instituições de ensino, cujo fechamento havia sido proposto por governos estaduais de São Paulo, Paraná, Rio de Janeiro, Goiás e Rio Grande do Sul, bem como melhorias nas condições educacionais, colocando na ordem do dia a educação como direito democrático e popular. Seu 
principal meio de manifestação foram as ocupações de escolas, o que gerou forte impacto midiático e suscitou o debate sobre a qualidade da educação pública no país.

Apesar do aumento de investimentos dos últimos anos, a qualidade do ensino público ainda está longe de ser satisfatória ${ }^{4}$. A ampliação do ensino médio, uma conquista demorada, vem sendo ameaçada pelas políticas adotadas a partir de 2016, cujo melhor exemplo seria a aprovação da Emenda Constitucional nº 95/2016, que estabeleceu o limite dos gastos públicos para os próximos 20, comprometendo os futuros investimentos em saúde e educação.

No entanto, não se deve generalizar toda a rede de ensino público como “de má qualidade”. Há exceções a esse quadro, ainda que pouco comentadas pela grande imprensa, e não imunes aos cortes de recursos e ataques às suas especificidades. Uma dessas exceções são as escolas de aplicação ligadas às Universidades públicas.

As escolas e colégios de aplicação dependentes de universidades públicas

As escolas de aplicação ligadas a Universidades públicas têm sua origem com o Decreto Federal n 9053, de 1946. Naquele ano, o país vivia o pleno processo de redemocratização, com o final do primeiro governo de Getúlio Vargas (1930-1945), momento que favorecia o debate sobre os rumos da educação brasileira e, em certa medida, a experimentação e a implementação de novas ideias.

A criação dessas escolas está inserida no movimento de renovação educacional iniciado com o Manifesto dos Pioneiros (1932), que ganha corpo na década de 1950 com o questionamento das bases e a estrutura do sistema educacional vigente. As críticas às funções da escola e os inúmeros debates geraram as condições objetivas para a criação de instituições (como o Inep e a Capes) que, por meio de pesquisas sobre a realidade do sistema educacional, tinham por objetivo modernizar o país. Nesse sentido, a implementação dos colégios de aplicação é produto de uma preocupação com a renovação pedagógica e habilitação de professores de educação média, construindo, assim, espaços para a experimentação e a demonstração pedagógico-didática, possibilitando a expansão de propostas educacionais para outras instituições de ensino.

Durante os vinte anos seguintes ao decreto de 1946, foram criadas a maioria das escolas em diferentes universidades federais: Colégio de Aplicação da Universidade de Rio de Janeiro (1948); Colégio de Aplicação da Universidade da Bahia (1949, extinto em 1976); Centro Pedagógico da Universidade de Minas Gerais (1954); Colégio de Aplicação da Universidade de Rio Grande do Sul (1954); Colégio de Aplicação da Universidade de Sergipe (1959); 
Colégio de Aplicação da Universidade de Santa Catarina (1961); Colégio Universitário da Universidade do Pará (1963); Colégio de Aplicação João XXIII da Universidade de Juiz de Fora (1965); Colégio de Aplicação da Universidade de Viçosa (1965); Centro de Ensino e Pesquisa Aplicada à Educação da Universidade Federal de Goiás (1966); Colégio Universitário da Universidade Federal do Maranhão (1968); Escola de Educação Básica da Universidade de Uberlândia (1977); Colégio de Aplicação da Universidade Federal do Acre (1981); Colégio de Aplicação da Universidade de Roraima (1995); e o Colégio Universitário Geraldo Reis da Universidade Federal de Fluminense (2006). No âmbito estadual, na década de 1950 é criada a escola que dará origem ao Colégio de Aplicação da Faculdade de Educação da Universidade de São Paulo e em 1960 o Colégio de Aplicação Pedagógica da Universidade Estadual de Londrina Prof. José Aloisio Aragão.

Atualmente, tais colégios atendem aos níveis infantil, primário, secundário e de educação de jovens e adultos, além do treinamento de professores e a experimentação e pesquisa pedagógicas. Assumem, como as Universidades das quais são parte, o compromisso de ensino, pesquisa e extensão (ao atuarem na formação de professores das redes municipal e estadual). No gráfico seguinte são apresentados os níveis atendidos por tais colégios.

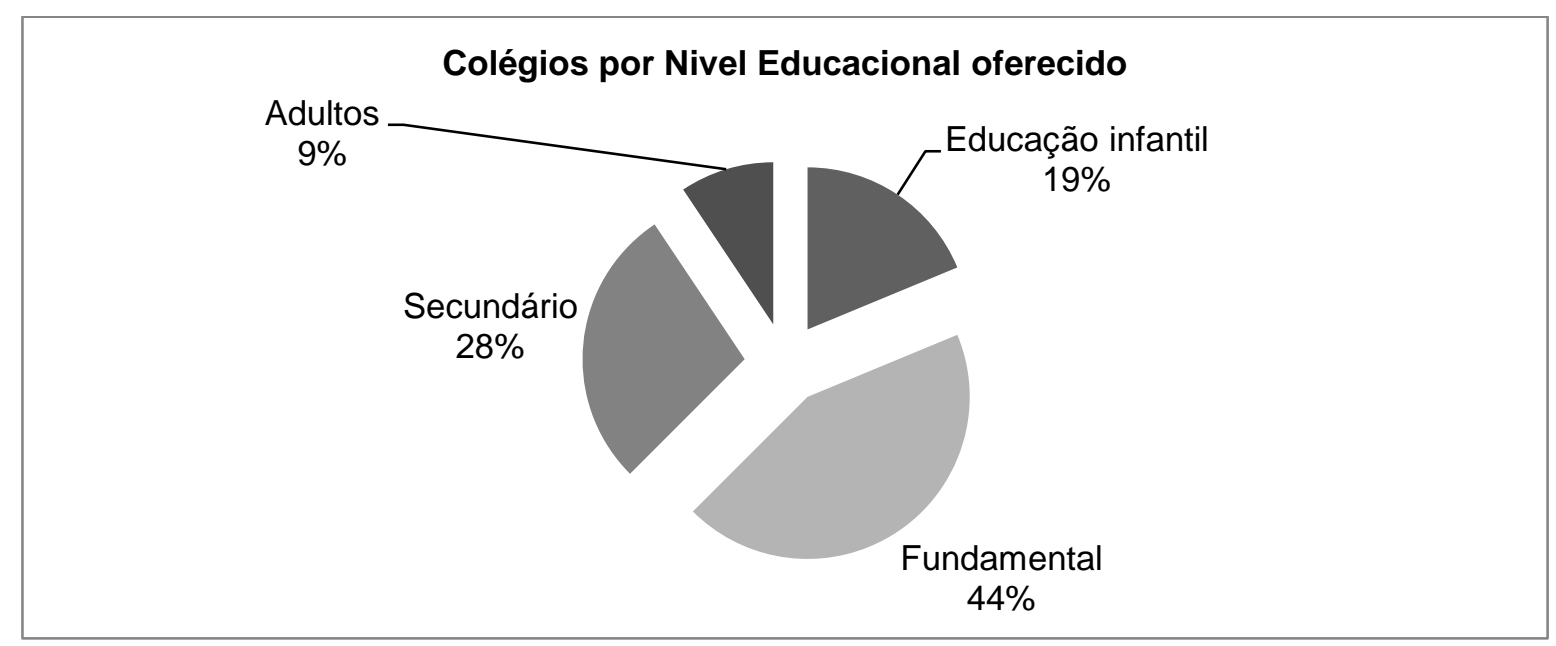

Gráfico 1. Colégios por nível educacional atendido (\%), uma instituição pode oferecer mais de um nível educacional. Elaboração própria a partir de informação disponível nas páginas web institucionais.

Por dependerem de Universidades públicas, as quais possuem autonomia em seu estatuto, as escolas de aplicação foram parcialmente preservadas de parte das reformas do nível secundário empreendidas pelo governo federal ao longo das últimas décadas, o que contribuiu para a continuidade, consistência, coerência e coesão de seu projeto pedagógicocurricular. Não obstante, a criação e/ou modificação dos planos de estudos desses colégios deve ser submetida à análise e aprovação da Secretaria de Educação correspondente, devendo estar em conformidade com as Diretrizes Nacionais de Educação Secundária. 
Além disso, o vínculo dos colégios com as Universidades (16 federais e duas estaduais) garantiu condições para a melhoria do processo de aprendizagem dos alunos, bem como salários acima da média da rede pública nacional e um regime de dedicação exclusiva (40 horas semanais, na maioria dos casos), que atrai os docentes, pois lhes possibilita o desenvolvimento de uma trajetória acadêmica, tendo em conta que o tempo de trabalho é dividido entre as aulas, a pesquisa e o acompanhamento dos estagiários. Os alunos dessas instituições têm, igualmente, acesso à infraestrutura dos campi universitários (laboratórios, equipamentos esportivos, áreas de lazer), o que não deixa de ser um diferencial com relação às demais escolas, sejam da rede pública ou estabelecimentos particulares.

Nesse contexto, essas escolas são consideradas, em conjunto com algumas escolas técnicas federais, colégios militares e poucos casos isolados de escolas das redes públicas estaduais, como "ilhas de excelência” no universo de escolas públicas brasileiras. Por exemplo, em 2015, 147 instituições públicas ficaram com melhores resultados no ENEM entre as 1.564 melhores colocadas do país. Do grupo de escolas públicas melhor classificadas, $67 \%$ eram escolas federais e 31\% estaduais, cuja maior parte das escolas era formada por escolas técnicas ${ }^{5}$. Ao longo dos anos, a maioria dos colégios de aplicação vem obtendo notas do Ideb acima da média dos municípios nos quais estão localizados.

Tendo em conta o diferencial de qualidade apresentado por esses colégios, a demanda por vagas supera sua oferta, o que levou à necessidade de elaboração de processos seletivos de ingresso. A maioria desses colégios adotam como meio de ingresso o sorteio aberto à comunidade (76\%), garantindo, por sua vez, cotas para filhos de funcionários ou servidores da Universidade à qual pertencem. Quando há processo seletivo baseado em exames (em 18\% das instituições analisadas) são avaliadas competências de língua portuguesa e matemática. A avaliação das condições socioeconômicas dos aspirantes é utilizada como critério de ingresso em 6\% das escolas dependentes de Universidades públicas. Algumas instituições reservam, ainda, vagas para alunos com algum tipo de deficiência.

A maior parte das escolas de aplicação evita a seleção de alunos por meio de exames de ingresso, buscando viabilizar o acesso de famílias de menores condições socioeconômicas, cumprindo, ainda que parcialmente, com o compromisso de inclusão por meio da educação, o que contraria a prática seletiva comum às Universidades das quais dependem, baseadas nos vestibulares e, mais recentemente, também no ENEM.

A seguir, será apresentado o caso de uma escola dependente de Universidade pública, a Escola de Aplicação da Faculdade de Educação da Universidade de São Paulo. 


\section{A Escola de Aplicação da USP}

As origens da Escola de Aplicação da Universidade de São Paulo (EA-USP) estão ligadas ao movimento de renovação educacional que dominou a década de 1950. Em 1958 foi criado um curso experimental pelo Centro Regional de Pesquisas Educacionais de São Paulo (CRPE-SP), ligado ao Instituto Nacional de Estudos Pedagógicos (Inep), para o primeiro ano do nível primário, com 28 alunos provenientes da Escola Alberto Torres, próxima ao campus da USP (ZAIA, 2003). O mencionado curso desempenharia também a função de escola de demonstração, sendo considerado um laboratório para aplicação de novas técnicas e métodos de ensino. Alunos dos cursos de formação de professores e outros profissionais da área poderiam utilizar a instituição como “campo de observação”.

Com a reforma universitária de 1969, a Universidade de São Paulo passou por mudanças estruturais, entre as quais se destacou a criação da Faculdade de Educação (FEUSP). O seu regulamento interno estabeleceu que a FEUSP manteria uma escola de Educação Primária e Secundária de acordo com os termos do Regulamento Geral da USP. Com a extinção do CRPE-SP, a escola de demonstração ligada àquele centro foi incorporada à USP, em 1972, passando a ser mantida pela FEUSP, denominando-se a partir de então “Escola de Aplicação de $1^{\circ}$ e $2^{\circ}$ graus” (ROSA, 2005). Ao ser incorporada à Universidade de São Paulo, a EA-USP passou a ter um regulamento próprio, aprovado pela Congregação da FEUSP.

Em 1985, a EA-USP implementou o curso secundário, oferecendo aos estudantes de nível primário a possibilidade de continuar seus estudos na instituição. Para acomodar o novo contingente de alunos, as dependências da escola foram ampliadas, com a construção de um novo edifício, na década de 1990. Atualmente, a escola conta com capacidade para atender entre 720 e 740 alunos, distribuídos em onze turmas de primeiro a quinto ano e oito turmas de sexto a nono ano, além de seis turmas de primeiro a terceiro ano do ensino médio. Cada ano pode ter até 60 alunos matriculados, divididos em duas turmas.

Com o objetivo de adequar a escola às orientações da LDB/96, a estrutura e funcionamento da instituição é modificada, implementando-se o ensino por ciclos. Seu nome oficial passa a ser Escola de Aplicação de Ensino Fundamental e Médio da Faculdade de Educação da Universidade de São Paulo. Em 1997, aproximadamente a metade do corpo docente da EA-USP foi renovado e mudanças na direção e administração da escola foram adotadas. Segundo Rosa (2005), tais fatos seriam resultado das discussões em torno dos objetivos pedagógicos da instituição, que se materializaram em um novo regulamento, aprovado em 1998. 

público.

Nesse contexto de mudanças, o cotidiano escolar foi marcado por instabilidade e contradição, convivendo o entusiasmo e a criatividade com a insegurança e a nostalgia. Se buscava uma “identidade”, mas, simultaneamente, se temia perder a qualidade idealizada por professores, funcionários e ex-alunos, os quais chegaram a formar, em 2000, uma associação, com o objetivo de ajudar a manter e inclusive melhorar a qualidade da educação oferecida pela EA-USP.

Em 1979, com adoção de seu primeiro Regulamento, a EA-USP estabeleceu como principal forma de ingresso de seus aspirantes o sorteio público, divididos em três categorias: funcionários e docentes da FEUSP (20 vagas); funcionários e docentes da USP (20 vagas); e 20 vagas para aspirantes fora dessas duas categorias - totalizando 60 vagas para cada ano. Pelo atual regulamento (de 2006), as vagas para matrícula no ensino médio são reservadas aos alunos que concluíram o ensino fundamental na escola. As vagas não preenchidas no nível médio (seja por transferência do aluno a outra instituição, repetência ou evasão), são sorteadas, de acordo com a categoria do aluno que não ocupou a vaga. Aproximadamente 1000 famílias participam, a cada ano, do sorteio por vagas na Aplicação (Plano Escolar 2013).

De acordo com os dados disponíveis, os alunos da EA-USP residem em diferentes áreas do Município de São Paulo e em outros municípios da área metropolitana paulista. A heterogeneidade característica da instituição “propicia a realização de um projeto de escola pública para todos, um verdadeiro exemplo de integração social e cultural” (GALVÃO, 1999, 3). Segundo Rosa (2005), estas características convertem a EA-USP em uma instituição próxima à realidade de outras escolas públicas paulistanas no que diz respeito à heterogeneidade socioeconômica e cultural dos estudantes.

Segundo levantamento realizado junto aos alunos do ensino médio em 2016, 153 estudantes (dos 180 matriculados) recebiam alguma bolsa de auxílio escolar para garantir sua participação nas atividades escolares. Foram concedidas 95 bolsas de material escolar, 37 bolsas de atividades didáticas (alimentação, hospedagem e ingressos para trabalhos de campo), 137 bolsas para alimentação no restaurante da USP, 120 bolsas para lanche na cantina escolar e 109 bolsas para a aquisição do uniforme escolar. Em trabalho de Alencar (2011), se indica que, em 2011, dos 180 estudantes matriculados, havia 47 alunos que recebiam alguma bolsa da Coordenação de Assistência Social da Universidade de São Paulo (COSEAS). Ou seja, em cinco anos se passou de 26,1\% de alunos bolsistas para 85\%.

A Escola de Aplicação se localiza em área contígua à Faculdade de Educação no Campus da Cidade Universitária da USP. Seus alunos recebem credencial de identificação da 
USP e possuem os mesmos direitos que qualquer aluno de graduação ou pós-graduação no que tange à utilização da infraestrutura universitária (restaurante central com preço das refeições subsidiado, centro de práticas esportivas, quadras da Faculdade de Educação Física da USP, hospital universitário, etc.).

A EA-USP ocupa, atualmente, três blocos com 27 salas de aula. As aulas para o ensino médio são ministradas em salas-ambiente específicas para cada disciplina. Entre os blocos A e B situa-se um anfiteatro com capacidade para 242 lugares, além dos arquivos do Centro de Memória da EA. Em entrevistas realizadas com alunos da instituição, o espaço físico da escola é um elemento bastante valorizado e a sua situação geográfica, inserida em plena cidade universitária, é considerado um diferencial com relação à maioria das escolas do estado de São Paulo.

Com relação à gestão, o regulamento atual indica que o diretor e o vice-diretor, cujos mandatos duram dois anos, são escolhidos pela Congregação da FEUSP entre os docentes daquela faculdade e educadores da Escola de Aplicação, por meio de consulta aos funcionários e educadores da EA-USP, aos docentes da FEUSP e às famílias que têm filhos matriculados na escola. Uma vez habilitados (em termos acadêmico-profissionais), os candidatos à direção se inscrevem em chapas e suas candidaturas devem ser acompanhadas de uma Carta de Intenções. Tanto os processos de candidatura como a eleição da equipe de gestão são abertos à consulta da comunidade educativa.

Cabe destacar que, desde 1997, ou seja, pós-LDB, se observa uma preocupação em respeitar o princípio de gestão democrática, que se efetiva em várias instâncias de participação (como o Conselho de Classe, Associação de Pais e Mestres, o Grêmio Escolar e o Conselho de Escola) e estimula a participação, na maioria dos casos, de todos os agentes institucionais: professores, funcionários, alunos, familiares, direção e corpo docente da FEUSP, bem como o corpo de alunos da FEUSP.

As reformulações, alterações e incorporações realizadas no Regulamento Interno (2006) e no Plano Escolar (2013) ilustram mudanças na gestão institucional, nas metodologias de ensino e na avaliação dos alunos, com o objetivo de escutar os verdadeiros protagonistas da instituição. A implementação de metodologias interdisciplinares (estudos do meio) e variados projetos como "Sexualidade", “Negritude” e "Prevenção ao Uso de Drogas” 6 responde, igualmente, às demandas da população estudantil, além de auxiliar na formação dos estudantes, ao articular teoria e prática em contextos concretos. 

público.

A seleção dos professores da EA é realizada conforme as normas estabelecidas pela Universidade de São Paulo. Aos professores em exercício se aplicam os direitos, deveres e o regime disciplinar procedentes das normas gerais organizadoras da Universidade, atendendo às peculiaridades da EA-USP. Os professores são contratados em jornadas de 40 horas semanais, com a carga horária dividida entre a docência, aperfeiçoamento profissional, pesquisa, preparação de aulas e atendimento aos estudantes. Rosa (2005) manifesta que entre os educadores da Aplicação, a formação contínua é uma constante e dispõe do acompanhamento da direção da escola. Muitos docentes realizam pesquisas de mestrado e doutorado (alguns mesmo tendo a escola como objeto de pesquisa). Vários educadores da EAUSP atuam como docentes em cursos de formação continuada para professores da rede pública. Uma outra característica do corpo docente da escola é a sua relativa estabilidade, já que a maioria dos professores permanece na instituição por mais de dez anos.

No atual regulamento, se estabelece que a carga horária mínima é de 800 horas, distribuídas por um mínimo de 200 dias de trabalho escolar efetivo. Segundo a matriz curricular, as aulas têm início às 7h20 horas e terminam às 13h. A duração de cada aula é de 50 minutos. Anualmente, estima-se um total de 1.133 horas de aulas.

Durante os três anos do nível médio, as matérias Língua Portuguesa e Literatura e Matemática têm uma duração de quatro horas semanais e o resto das matérias duas horas semanais cada. Os estudantes podem optar pelo idioma inglês, francês ou espanhol. Existe também a implementação de um projeto interdisciplinar, de duas horas semanais, envolvendo todas as áreas do conhecimento em um trabalho integrado.

Apesar do compromisso de seu corpo docente e diretivo, a EA-USP não estaria imune aos problemas que afetam o sistema educacional público brasileiro. A falta de professores e a descontinuidade de projetos educacionais é uma realidade cada vez mais presente ${ }^{7}$, resultado da precária situação financeira da USP. Áreas como biologia, física e química são as mais afetadas pela falta de docentes, e as aulas de geografia e história chegaram a ser atribuídas a professores de outras disciplinas.

Em referência aos procedimentos de acompanhamento e avaliação dos estudantes, é adotado o sistema de progressão seriada, no qual o aluno que obtenha desempenho global insatisfatório, segundo o Conselho de Classe, pode repetir em qualquer ano. A frequência é condição para a promoção, ficando retido o aluno que tenha, ao finalizar o ano letivo, comparecimento menor que $75 \%$ do total de aulas de uma ou mais disciplinas, conforme análise e decisão do Conselho de Classe. 
O Plano Escolar 2013 registra o desempenho dos estudantes de educação básica durante o período 2004-2012, incluindo aprovações, reprovações e abandono. No quadro seguinte, se destaca os resultados do nível médio que, com exceção de alguns períodos letivos (2006, 2007 e 2011), o percentual de alunos aprovados é bastante alto e a taxa de evasão, baixíssima.

\begin{tabular}{|c|c|c|c|}
\hline \multicolumn{4}{|c|}{ Taxa de Aprovação/ Reprovação / Abandono do nível médio (\%) } \\
\hline Ano & Aprovação & Reprovação & Abandono \\
\hline 2004 & 97,33 & 2,67 & 2,14 \\
\hline 2005 & 95,72 & 2,14 & 0,57 \\
\hline 2006 & 85,23 & 14,20 & 1,1 \\
\hline 2007 & 89,01 & 9,89 & 1,1 \\
\hline 2008 & 88,3 & 10,6 & - \\
\hline 2009 & 93,05 & 6,95 & 2,32 \\
\hline 2010 & 91,98 & 5,70 & 1,66 \\
\hline 2011 & 88,33 & 11,66 & 1,12 \\
\hline 2012 & 95,53 & 4,47 & \\
\hline
\end{tabular}

Tabela 1. Elaboração própria a partir do Plano Escolar 2013 da EA.

Em 2015, a Aplicação alcançou o primeiro lugar no índice Ideb entre as escolas públicas da capital paulista para o nível primário. Para a diretora da Escola, em entrevista concedida naquele ano, conquistar o primeiro lugar teria uma importância enorme para toda a comunidade escolar, ao reconhecer a formação brindada pela escola, apesar das dificuldades na reposição de professores.

Em apoio às aulas regulares, foram implementadas, no contraturno, distintas estratégias para melhorar o desempenho dos educandos: "Projeto de Recuperação”, "Plantões de Dúvidas Semanais”, “Orientação de Estudos, “Aulas de Recuperação Disciplinar” e outras atividades desenvolvidas na Faculdade de Educação por professores, estagiários ou outros agentes designados pelo diretor da EA-US (Plano Escolar 2013).

De acordo com o estabelecido pela CF/1988 e outros documentos oficiais ${ }^{8}$, o Plano Escolar vigente deve incluir uma proposta de inclusão de estudantes com necessidades 
educativas especiais. Em 2013, 13 estudantes dessa categoria estavam matriculados na EA, estando 4 no nível secundário ${ }^{9}$.

Para uma atenção especializada a esse público escolar, existe um espaço de tutorias de duas horas no contra turno escolar para ajudar os estudantes na realização das tarefas pedidas pelos professores nas aulas. Também se realizam entradas programadas nas salas de aula, com o objetivo de colaborar com os professores no oferecimento e acompanhamento de atividades inclusivas, pensadas para atender à heterogeneidade das turmas e avaliar o processo educacional dos estudantes. A equipe de profissionais de educação inclusiva está conformada por uma psicóloga escolar, uma pedagoga com formação em letras (Linguagem Brasileira de Sinais - LIBRAS) e uma enfermeira.

Desde 2013, o foco de análise nas reuniões pedagógicas tem sido o trabalho com a diversidade, pois a grande heterogeneidade existente no corpo discente da escola vem provocando problemas nas relações interpessoais, sendo motivo de conflitos a orientação sexual, a obesidade, a religião e a questão social, entre outros. A partir desse diagnóstico, os profissionais da escola trabalharam intensivamente com os alunos o tema da discriminação, como relatou na entrevista a coordenadora de pesquisa da EA-USP, em fevereiro de 2014.

\section{Considerações Finais}

Em trabalho de campo realizado junto à Escola de Aplicação da USP, entre 2014 e 2016, foram realizadas entrevistas individuais e em grupo a alunos, professores e equipe de gestão, além de pesquisas de opinião a alunos do primeiro e último anos do ensino médio. No total foram realizadas 109 pesquisas de opinião e 46 entrevistas (35 alunos, 8 professores e 3 membros da equipe diretiva).

Em linhas gerais, os alunos da EA-USP valorizam o fato de estudarem em uma "escola pública e de qualidade”, que os forma em “valores e normas” com "professores com boa formação”, ou seja, destacam que a instituição se diferencia no universo de escolas da rede pública paulista. A instituição é vista como “diferenciada” das demais escolas da rede pública, em razão das propostas didáticas, dos recursos materiais e humanos, da infraestrutura existente na Cidade Universitária, da disponibilidade de aulas de idiomas, experiências em cursos de extensão, acompanhamento e apoio extraclasse.

Ao serem perguntados sobre as preferencias, os alunos indicaram a área de esportes (CEPEUSP), as atividades de extensão e os companheiros. Já com relação ao que consideram 
“mais importante” na escola, manifestaram ser os conteúdos ensinados, os valores trabalhados e a disciplina nos estudos. Ou seja, elementos de autonomia e conscientização.

O ensino médio é visto, pela maioria dos alunos da EA-USP, como tendo função primordial a preparação para o ensino superior. Nesse ponto, muitos dos entrevistados consideraram que a escola teria condições de ser academicamente mais exigente, contribuindo para um melhor desempenho no vestibular ou no ENEM. Mas não se trata de consenso: alguns estudantes demandam uma escola com uma abordagem mais profunda de determinados conteúdos, que seja mais rigorosa com a entrega dos trabalhos, que ensine mais que "o mínimo"; outros estariam satisfeitos com o volume de conteúdo trabalhado. Um grupo menor de alunos manifestou a opinião de que a escola os prepararia para uma melhor inserção no mercado de trabalho.

Muitos estudantes destacaram a contribuição da instituição para a formação de una consciência reflexiva, o que lhes possibilitaria ter uma "posição frente ao mundo”. Em linhas gerais, se evidencia que no momento de escolher onde estudar, os alunos valorizam uma instituição onde possam canalizar seus desejos de aprender, que a qualidade da proposta acadêmica seja superior à oferecida em outros estabelecimentos, que os professores tenham boa formação e, inclusive, seja um espaço de socialização valioso.

Diferentemente da opinião generalizada de que os estudantes estariam pouco interessados ou comprometidos com o saber, a opinião expressa pelos alunos permite concluir que a escola secundaria se converte em um espaço significativo de aprendizagem tanto de conhecimentos (formação política, idiomas, viajes de estudos) como de valores e normas. Desprende-se, assim, que o valor do conhecimento não é questionado pelos alunos, quando transmitido em condições adequadas e por profissionais comprometidos.

Além da função preparatória para o ingresso no ensino superior, os alunos indicaram que no nível médio é possível preparar-se igualmente para a vida adulta -adquirir autonomia, responsabilidade, compromisso -, falar e entender-se com pares e adultos, conhecer e fazer valer seus direitos. Em sua grande maioria, os alunos encontram, em sua escolarização, conteúdos significativos, professores bem formados, boa infraestrutura e recursos, propostas de trabalho interessantes e inovadoras, além de construir laços de amizade e companheirismo em um ambiente marcado pela diversidade.

Podemos considerar, portanto, que quando há uma escola pública de qualidade, com docentes comprometidos e motivados, o questionamento sobre o "sentido" da educação em 

público.

nível secundário deixa de ser relevante e a verdadeira questão passa a ser como aproveitar as boas práticas existente para melhorar esse sistema como um todo.

Nesse sentido, seria importante recuperar a ideia de que as escolas de aplicação têm como um de seus objetivos fundacionais (conforme a lógica dos pioneiros da reforma da educação) a produção de conhecimentos que sirvam de parâmetros para outras escolas públicas, sendo um tipo de escola orientada, em seu cotidiano, para a pesquisa em Educação, através das práticas de professores, orientadores e diretores, assim como de grupos de pesquisadores internos e externos à escola. Assim, uma das missões dessas escolas seria justamente contribuir, com suas boas práticas, pesquisas e inovações, para a melhoria geral da rede pública escolar na direção de uma escola inclusiva e democrática, que possibilite superar o "falso dilema" de falta de sentido do ensino médio para os alunos das camadas de menor renda da população brasileira

\footnotetext{
Notas

${ }^{1}$ Trata-se de um fenômeno que não se restringe aos países latino-americanos. Nos Estados Unidos, a crítica ao "high school” também é uma constante (ver, por exemplo https://www.vice.com/en_us/article/j53vnk/thehistory-of-the-future-of-high-school-v25n3 Acesso em 17 out. 2018.

2 "Os sentidos do ensino médio em Escolas dependentes de Universidades públicas. As percepções de estudantes, professores e diretores sobre colégios universitários dependentes da Universidade de Buenos Aires e da Universidade de São Paulo", defendida e aprovada em julho de 2018, na Faculdade de Ciências Sociais da Universidade de Buenos Aires.

${ }^{3}$ O percentual de gastos em educação com relação ao PIB chegou a 5,8\% em 2010, contra 4,6\% em 2006, Em 2013 atingiu 6,6\%. Disponível em http://www1.folha.uol.com.br/educacao/2015/04/1612236-gasto-publico-emensino-atinge-66-do-pib-mas-crise-ameaca-expansao.shtml Acesso em 10 out. 2015.

${ }^{4}$ Os dados do Ideb 2017 (Índice de Desenvolvimento da Educação Básica) - que se baseia no desempenho dos alunos das redes privada e pública em provas de português e matemática e nos índices de aprovação, e é divulgado a cada dois anos pelo Ministério da Educação - indicaram que o ensino médio apresenta o pior desempenho da educação de base brasileira, com um índice geral de 3,8 (abaixo da meta fixada para 2017, de 4,7). Os dados revelam que nenhuma unidade da federação atingiu a meta proposta para o ensino médio e que a evolução do nível se encontraria estagnada, tendo em conta que em 2011, 2013 e 2015 o índice foi de 3,7.

${ }^{5}$ http://www1.folha.uol.com.br/educacao/2015/08/1664666-presenca-de-escolas-publicas-entre-as-melhores-doenem-cresce-novamente.shtml?cmpid=bnfolha Acesso em 05 ago. 2015.

${ }^{6}$ Em 2017, esses projetos foram interrompidos por problemas orçamentários da EA em razão da grave crise financeira enfrentada pela USP.

7 https://www.bemparana.com.br/noticia/escola-modelo-da-usp-tem-falta-de-professores-e-alunos-semaula\#.Xa4soi3SH-Y Acesso em 22 out 2017.

${ }^{8}$ Lei de Diretrizes e Bases da Educação Nacional no 9394/96; Parâmetros Curriculares Nacionais; Política Nacional de Educação Especial na perspectiva da Educação Inclusiva, entre outros.

9 Os dados mais recentes registram 12 alunos com necessidades especiais na EA-USP, vide http://www.qedu.org.br/escola/190470-escola-de-aplicacao-da-faculdade-de-educacao-da-usp Acesso em 05 set 2018.
}

\section{Referências}

ADORNO, Theodor. W. Capitalismo tardio ou sociedade industrial. In: COHN, Gabriel. Theodor Adorno. São Paulo: Ática, 1986. p. 62-75. 
ADORNO, Theodor. W. A técnica psicológica das palestras radiofônicas de Martin Luther Thomas [1943]. (I Parte: O elemento pessoal: caracterização do agitador) [Gesammelte Schriften Vol. 9, tomo II (Soziologiche Schriften II). Frankfurt: Suhrkamp Verlag, 1975, pp. 11-37 - Tradução de Francisco Rüdiger.). Disponível em: https://www.marxists.org/portugues/adorno/ano/mes/palestras.htm Acesso em 06 set. 2019.

ADORNO, Theodor. W. A teoria freudiana e o padrão da propaganda fascista. Publicado originalmente em Psychoanalysis and the Social Sciences 3 (408-433) 1951. Reproduzido em Gesammelte Schriften Vol. 8, T. I. Tradução: Gustavo Pedroso. In: Margem esquerda - ensaios marxistas. N. ${ }^{\circ}$ 07. São Paulo: Boitempo, 2006b. p. 164-189.

ADORNO, Theodor. W. Educação e emancipação. 4ª Ed. São Paulo: Editora Paz e Terra, 2006.

ADORNO, Theodor. W. Palavras e sinais. Modelos críticos 2. Petrópolis: Vozes, 1995.

ADORNO, Theodor. W. Teoria da semicultura. Tradução de Newton Ramos-de-Oliveira, Bruno Pucci e Cláudia B. M. de Abreu. In: Revista Educação e Sociedade nº. 56, ano XVII, p. 388-411, 1996.

ADORNO, Theodor. W. Terminologia filosófica. Vol. I. Madrid: Taurus, 1976.

ADORNO, Theodor. W. Terminologia filosófica. Vol. II. Madrid: Taurus, 1977.

ANTUNES, Ricardo; PINTO, Geraldo Augusto. A fábrica da educação: da especialização taylorista à flexibilização toyotista. São Paulo: Cortez, 2017. (Coleção questões da nossa época; v. 58).

CASAGRANDA, Edilson Alencar; Rossetto, Miguel da Silva. Da Paideia à Bildung pelo trajeto do "cuidado de si”: formação como autoformação. In: DALBOSCO, Claudio Almir; MÜHL, Eldon Henrique; FLICKINGER, Hans-Georg (Orgs.). Formação humana (Bildung): despedida ou renascimento? São Paulo: Cortez, 2019. p. 93-112.

CASSIO, Fernando (Org.). Educação contra a barbárie: por escolas democráticas e pela liberdade de ensinar. 1. ed. São Paulo: Boitempo, 2019.

DALBOSCO, Claudio Almir; MÜHL, Eldon Henrique; FLICKINGER, Hans-Georg (Orgs.). Formação humana (Bildung): despedida ou renascimento? São Paulo: Cortez, 2019.

FREITAG, Barbara; ROUANET, Sérgio Paulo. Política educacional e indústria cultural. 2. ed. São Paulo: Cortez, 1989.

GEORGEN, Pedro. Bildung ontem e hoje: restrições e perspectivas. In: DALBOSCO, Claudio Almir; M6UHL, Eldon Henrique; FLICKINGER, Hans-Georg (Orgs.). Formação humana (Bildung): despedida ou renascimento? São Paulo: Cortez, 2019. p. 15-34.

GIOCAIA JUNIOR, Oswaldo. A Educação em Nietzsche e Adorno. In: PUCCI, Bruno, ALMEIDA, Jorge \& LASTÓRIA, Luiz Antônio Calmon. Experiência formativa \& emancipação. São Paulo: Nankin, 2009. p. 37-67.

HARVEY, David. A loucura da razão econômica: Marx e o capital no século XXI. São Paulo: Boitempo, 2018.

HARVEY, David. O enigma do capital: e as crises do capitalismo. São Paulo: Boitempo, 2011.

HORKHEIMER, Max e ADORNO, Theodor W. Dialética do Esclarecimento. Rio de Janeiro: Jorge Zahar Ed., 1985.

HORKHEIMER, Max. Eclipse da razão. São Paulo: Centauro, 2000. 
HORKHEIMER, Max. Filosofia e teoria crítica. In: HORKHEIMER, Max; ADORNO, Theodor W. Textos escolhidos. 5. ed. São Paulo: Nova Cultural, 1991. p. 69-75 (Os pensadores; 16).

JAY, Martin. As idéias de Adorno. São Paulo: Cultrix: Editora da universidade de São Paulo, 1988.

KANT, Immanuel. Textos seletos. $4^{\text {a }}$ Ed. Petrópolis, RJ: Vozes, 2008, p. 63-71.

LAVAL, Christian. A escola não é uma empresa: o neoliberalismo em ataque ao ensino público. São Paulo: Boitempo, 2019

MAAR, Wolfgang Leo. Educação crítica, formação cultural e emancipação política na Escola de Frankfurt. In: PUCCI, Bruno (org.). Teoria crítica e educação: a questão da formação cultural na Escola de Frankfurt. Petrópolis, RJ: Vozes; São Carlos, SP: EDUFISCAR, 1995. p. 59-81.

MARCUSE, Herbert. A ideologia da sociedade industrial: o homem unidimensional. 4. ed. Rio de Janeiro: Zahar Editores, 1973.

NOBRE, Marcos. A teoria crítica. 2. ed. Rio de Janeiro: Zahar, 2008.

PERIUS, Oneide. Esclarecimento e dialética negativa: sobre a negatividade do conceito em Theodor W. Adorno. Coleção Diá-logos 12. Passo Fundo: Instituto Superior de Filosofia Berthier, 2008.

PUCCI, Bruno (org.). Teoria crítica e educação. A questão da formação cultural na Escola de Frankfurt. Petrópolis, RJ: Vozes; São Carlos, SP: EDUFISCAR, 1995.

PUCCI, Bruno, RAMOS-DE-OLIVEIRA, Newton \& ZUIN, Antônio Álvaro Soares. Adorno: o poder educativo do pensamento crítico. 2. ed. Petrópolis, RJ: Vozes, 1999.

PUCCI, Bruno, GOERGEN, Pedro \& FRANCO, Renato (Org.). Dialética negativa, estética e educação. Coleção educação em debate. Campinas, SP: Editora Alínea, 2007.

PUCCI, Bruno, ALMEIDA, Jorge \& LASTÓRIA, Luiz Antônio Calmon. Experiência formativa \& emancipação. São Paulo: Nankin, 2009.

SANTOMÉ, Jurjo Torres. A educação em tempos de neoliberalismo. Porto Alegre: Artmed, 2003.

TEODORO, António. A educação em tempos de globalização neoliberal: os novos modelos de regulação das políticas educacionais. Brasília: Liber Livro, 2011.

THOMSON, Alex. Compreender Adorno. Petrópolis, RJ: Vozes, 2010. (Série Compreender).

VILELA, Rita Amélia Teixeira. A teoria crítica da educação de Adorno e a sua apropriação para análise das questões atuais sobre currículo e práticas escolares. Relatório de pesquisa 2004-2006. PUC Minas, $2007 . \quad$ Disponível em: http://portal.pucminas.br/imagedb/mestrado_doutorado/publicacoes/PUA_ARQ_ARQUI20120828100 151.pdf. Acesso em: 06 set. 2019.

WIGGERSHAUS, Rolf. A Escola de Frankfurt: história, desenvolvimento teórico, significação política. 2. ed. Rio de Janeiro: DIFEL, 2006 
Informações sobre os Revisores:

\section{Língua $\quad$ Nome: Miriam Juliana Pastori Bosco \\ Portuguesa $\quad$ E-mail: miriam.bosco@ifpr.edu.br}

Língua Inglesa | Nome: Ingrid Trioni Nunes Machado E-mail: ingrid.machado@ifpr.edu.br

Língua Espanhola Nome: Daniel Carlos Santos da Silva E-mail:daniel.silva@ifpr.edu.br 